\title{
FRATURA DE AGULHA GENGIVAL: QUANDO REMOVER?
}

Lorena Goedert SPAK, Fernanda Brasil Daura Jorge BOOS, Gustavo Faria CERQUEIRA, Hedelson Odenir Iecher BORGES, Glaykon Alex Vitti STABILE

Os acidentes e complicações que podem ocorrer nos pacientes submetidos a tratamento odontológico são diversos. Fraturas de agulhas gengivais eram relativamente frequentes na década de 60, anterior à substituição das agulhas reutilizáveis e rígidas pelas atuais: descartáveis e flexíveis. Com essas mudanças este acidente tornou-se raro, sendo incomuns os relatos destes casos. Apesar disso, devem-se levar em consideração cuidados indispensáveis como realização correta da técnica anestésica, a profundidade de inserção e evitar dobras na agulha. O objetivo deste trabalho é apresentar o relato de dois casos clínicos de fratura de agulha gengival em região pterigomandibular, um tratado de forma conservadora e outro por meio de cirurgia para remoção do corpo estranho, além de discorrer sobre as suas implicações e quando deve ser feita a sua remoção.

Palavras chave: Fratura; Agulha; Acidente. 